\title{
Utilizing Practice-Based Research Networks to Teach and Implement Quality Improvement in Academic Medicine
}

\author{
Clarissa Hoff, MD, MPH; Luisito Caleon, MD, MPH; Grace Lee, MD, MPH; Mathew Quan, BS
}

\begin{abstract}
BACKGROUND AND OBJECTIVES: A 2019 study found that between 2014 and 2017, family medicine residents had little improvement in self-assessed preparedness to lead quality improvement projects. This study explored the effectiveness of leveraging a practice-based research network (PBRN) across multiple family medicine residencies not only for implementing quality improvement projects, but also as a teaching tool designed to improve knowledge, attitudes, beliefs, and leadership skills in family medicine faculty and residents.
\end{abstract}

METHODS: Residents in family medicine residency programs and one community internal medicine program and family medicine teaching faculty participated in a PBRN-led quality improvement project (QIP) to improve colon cancer screening in their clinic. Of 101 participants, 79 (78\%) were residents and 22 (22\%) were faculty or attending physicians. Questions surveying participants' knowledge and confidence related to QIP before and after the QIP were given.

RESULTS: Overall, participants reported an improvement in their basic understanding of QI concepts $(P=.004)$. They also reported having sufficient staff and ancillary support to meaningfully participate $(P=.033)$. Participants indicated they had more confidence in their ability to participate in a QI project $(P=.002)$, initiate, design, and lead such a project $(P=.001)$, and teach their peers and staff basic QI concepts $(P<.001)$.

CONCLUSIONS: PBRNs appear to be a unique way to subjectively improve residents' confidence in their quality improvement skills. PBRNs should be further explored as a method for educating family medicine residents in quality improvement.

(Fam Med. 2020;52(9):642-6.)

doi: 10.22454/FamMed.2020.411271

A s recognized by the Accreditation Council for Graduate Medical Education (ACGME), ${ }^{1}$ quality improvement (QI) projects are a critical and standard component of family medicine residency training. QI projects (QIP) not only have the capacity to improve patient outcomes and delivery of care, ${ }^{2}$ but they also have the training, future generations of physicians will possibly be able to develop and lead evidence-based QIPs in their own practices, thereby continuously engaging in efforts to improve patient care, ${ }^{3}$ and enhancing population-based medicine within their clinic settings.

The current state of teaching QI to residents, however, seems ineffective in providing educationally meaningful outcomes. Implementing a longitudinal QI curriculum for their family medicine residents, Potts et $\mathrm{al}^{4}$ demonstrated little improvement in the residents' self-rated ability to analyze their practice using QI methods. Similarly, a 2019 study found that between 2014 and 2017, family medicine residents had little improvement in self-assessed preparedness to lead QI projects. ${ }^{5}$ In order to bridge the gap for the residents and help them in future QI projects, new and innovative ways to teach QI to family medicine faculty and residents are needed. The Agency for Healthcare Research and Quality states they support

the practice-based research network's] ability to improve the health of all Americans, and the potential of these networks to engage clinicians in quality improvement activities. ${ }^{6}$

Evidence supporting the utility a practice-based research network (PBRN) as a teaching tool for
From the Department of Family and Community Medicine, Tulane University, New Orleans, LA 
QI is unknown. Southern Area Patient Oriented Research Organization (SAPORO), a PBRN that focuses on primary care clinics in the Gulf South region, conducted a multicenter QI project to increase colorectal cancer screening in the primary care setting. In this study, we investigated the effectiveness of utilizing a PBRN across multiple family medicine teaching sites (six family medicine residency programs and one family medicine clinic) for not only implementing QI projects but also as a teaching tool designed to improve knowledge, skills, and attitudes in family medicine faculty and residents.

\section{Methods}

The Tulane University Institutional Research Review Board approved this quality improvement project as exempt. We took the knowledge, attitudes, and beliefs data for this study from a pre- and postsurvey done as part of a QIP to improve colorectal cancer screening in primary care clinics. This was an optional QI project to improve colorectal cancer (CRC) screening rates according to United States Preventive Service Task Force Guidelines offered to both residents and faculty continuity clinics across six family medicine residency programs and one family medicine faculty department who teach in a medical school, and one private family medicine clinic who is an active preceptor of medical students. All clinics were located in Louisiana and were also members of the SAPORO PBRN. One internal medicine residency program associated with a family medicine residency program asked to participate and was allowed to join for this project. No consent was needed for the study and a waiver was obtained, as no patient identifying data was collected as part of this QIP.

Each participating clinician completed a preintervention and postintervention survey hosted on a Health Insurance Portability and Accountability Act-compliant, cloudbased survey database. The survey involved gathering baseline CRC screening rates of patient populations; quantitative and qualitative data on the feasibility of QI projects in the physician's clinic; barriers to improving colon cancer screening rates; and assessment of physicians' knowledge, attitudes, and beliefs about QI. We sent clinicians personalized, secure links to access their respective surveys.

We allowed each clinic site the freedom to choose two or more evidence-based QI interventions deemed appropriate to the clinic. Interventions for CRC screening varied by each site, though all sites utilized some form of print materials such as promotional pamphlets and posters by the Centers for Disease Control and Prevention, fecal immunochemical test kit instructions, and informational pocket cards for physicians to use with patients. Some sites had additional intervention components such as nurse staff education, a walk promoting colon cancer awareness, phone calls to eligible patients, or a dedicated medical assistant for the QI project. We carried out the implemented intervention for a minimum of 2 months. Table 2 demonstrates overall flow of the PBRN-implemented QIP, what educational interventions were done to educate the PBRN participants, when data was collected, and when it was dispersed to the participating sites.

We collected new data on the screening rates after implementation of the intervention. We utilized SPSS Statistics (IBM SPSS, Inc, Armonk, NY) to determine descriptive statistics and to analyze the data for any correlations. We presented preliminary data to the SAPORO Network as a whole during an annual research day.

Finalized data and site-specific data were presented to each clinic individually along with a review of which interventions were most effective in improving screening rates.

\section{Results}

We invited 219 participants to participate in the QI project, and complete data were available for 101 participants. Of 101 participants, 79 (78\%) were residents, and $22(22 \%)$ were faculty or attending physicians. Of the residents, 36 (46\%) were interns at the start of the QI project, and $43(54 \%)$ were in their second postgraduate year of training. All participants completed surveys and submitted CRC screening data on 10 patients both prior to and following the QI intervention.

Table 1: Inclusion and Exclusion Criteria

\begin{tabular}{|c|c|}
\hline \multicolumn{1}{|c|}{ Inclusion Criteria } & Exclusion Criteria \\
\hline - Faculty and residents practicing in a & - Faculty or residents who do not have an active practice in an outpatient \\
SAPORO clinic & clinic associated with SAPORO \\
- In good standing with their respective & - Faculty or residents not in good standing or those with restricted \\
clinic and/or university & licensure \\
- Must directly care for patients in a & - Time spent in clinics not associated with SAPORO by a SAPORO \\
SAPORO clinic setting or directly & clinician is not to be included in the demographic study. \\
oversee residents/students in such a & - Patient care time spent in inpatient or emergency care settings \\
setting & - Visiting faculty, residents doing an away rotation at a SAPORO clinic, \\
Has an active unrestricted license to & medical students, or other personnel not normally associated with the \\
practice in their area of expertise & SAPORO clinic \\
\hline
\end{tabular}

Abbreviation: SAPORO, Southern Area Patient-Oriented Research Organization. 
Table 2: Practice-Based Research Network Quality Improvement Cycle

\begin{tabular}{|l|l|l|l|l|}
\hline \multicolumn{1}{|c|}{ Step 1 } & \multicolumn{1}{|c|}{ Step 2 } & \multicolumn{1}{c|}{ Step 3 } & \multicolumn{1}{c|}{ Step 4 } & \multicolumn{1}{c|}{ Step 5 } \\
\hline $\begin{array}{l}\text { Lecture on United } \\
\begin{array}{l}\text { Stated Cancer Colon } \\
\text { Cancer Screening } \\
\text { Guidelines given to } \\
\text { each site }\end{array}\end{array}$ & $\begin{array}{l}\text { Surveys sent out and } \\
\text { data gathered on 10 } \\
\text { patients each }\end{array}$ & $\begin{array}{l}\text { Baseline data } \\
\text { presented for each } \\
\text { site }\end{array}$ & $\begin{array}{l}\text { QI interventions } \\
\text { implemented for each } \\
\text { site for a minimum of 2 } \\
\text { months }\end{array}$ & $\begin{array}{l}\text { Second survey is } \\
\text { sent out to gather } \\
\text { postintervention data }\end{array}$ \\
\hline $\begin{array}{l}\text { Descriptions of PBRN } \\
\begin{array}{l}\text { QIP and time for } \\
\text { questions to residents } \\
\text { and faculty at each } \\
\text { site }\end{array}\end{array}$ & $\begin{array}{l}\text { Each site selected } \\
\text { QI intervention that } \\
\text { feasible for their clinics }\end{array}$ & $\begin{array}{l}\text { Lecture on QI } \\
\text { Plan Do Study } \\
\text { Technique given }\end{array}$ & $\begin{array}{l}\text { Monthly phone } \\
\text { conferences held as } \\
\text { check-ins to problem } \\
\text { solve }\end{array}$ & $\begin{array}{l}\text { Postintervention } \\
\text { data is presented at } \\
\text { each site and at a } \\
\text { research day where } \\
\text { all PBRN participated } \\
\text { in research and QI } \\
\text { training }\end{array}$ \\
\hline
\end{tabular}

Abbreviations: PBRN, practice-based research network; QIP, quality improvement project.

Questions surveying participants' knowledge and confidence related to QI showed marked improvement following the QI project (Table 3). Overall, participants reported an improvement in a basic understanding of QI concepts $(P=.004)$. They also increasingly felt that they had sufficient staff and ancillary support to meaningfully participate in QI projects $(P=.033)$. Participants indicated they had more confidence in their ability to participate in a QI project $(P=.002)$; initiate, design, and lead such a project $(P=.001)$; and teach their peers and staff basic QI concepts $(P<.001)$.
Questions surveying the importance of QI generally had improved scores following the QI project, though only one question demonstrated statistically significant improvement in the response. Postintervention, participants felt more strongly that quality improvement improves patient outcomes $(P=.044)$.

Table 3: Survey Responses Assessing QI Knowledge, Attitudes, and Beliefs

\begin{tabular}{|c|c|c|c|c|c|c|c|c|c|c|}
\hline \multirow{2}{*}{\multicolumn{2}{|c|}{ QI Importance Questions }} & \multicolumn{3}{|c|}{ Overall } & \multicolumn{3}{|c|}{ Faculty } & \multicolumn{3}{|c|}{ Residents } \\
\hline & & & $\begin{array}{c}\text { Score } \\
\text { Got }\end{array}$ & & Score & $\begin{array}{c}\text { Score } \\
\text { Got }\end{array}$ & $P$ & Score & $\begin{array}{c}\text { Score } \\
\text { Got }\end{array}$ & \\
\hline 1 & $\begin{array}{l}\text { Quality improvement projects can } \\
\text { improve faculty and staff morale. }\end{array}$ & 30 & 30 & .539 & 27 & 23 & .831 & 30 & 32 & .445 \\
\hline 2 & $\begin{array}{l}\text { Quality improvement adds } \\
\text { unnecessary administrative burden } \\
\text { to my practice. }\end{array}$ & 37 & 22 & .131 & 41 & 14 & .071 & 35 & 24 & .356 \\
\hline 3 & $\begin{array}{l}\text { Quality improvement improves } \\
\text { patient outcomes. }\end{array}$ & 27 & 14 & .044 & 32 & 9 & .083 & 25 & 15 & .158 \\
\hline 4 & $\begin{array}{l}\text { Participating in the quality } \\
\text { improvement process helps prevent } \\
\text { burn out. }\end{array}$ & 30 & 28 & .600 & 32 & 18 & .507 & 29 & 30 & .705 \\
\hline 5 & $\begin{array}{l}\text { Participating in quality } \\
\text { improvement can help faculty and } \\
\text { staff feel more engaged and excited } \\
\text { about their job. }\end{array}$ & 34 & 28 & .521 & 41 & 5 & .052 & 32 & 34 & .869 \\
\hline 6 & $\begin{array}{l}\text { Quality improvement has a } \\
\text { meaningful positive impact on me } \\
\text { as a physician. }\end{array}$ & 30 & 31 & .836 & 23 & 32 & .439 & 32 & 30 & .604 \\
\hline 7 & $\begin{array}{l}\text { Quality improvement is has } \\
\text { meaningful positive impact on my } \\
\text { patients. }\end{array}$ & 31 & 17 & .112 & 36 & 18 & .356 & 29 & 16 & .189 \\
\hline 8 & $\begin{array}{l}\text { Participating in quality } \\
\text { improvement is essential for } \\
\text { my ongoing development as a } \\
\text { physician. }\end{array}$ & 31 & 26 & .282 & 32 & 14 & .131 & 30 & 29 & .634 \\
\hline
\end{tabular}


Table 3: Continued

\begin{tabular}{|c|c|c|c|c|c|c|c|c|c|c|}
\hline \multirow{2}{*}{\multicolumn{2}{|c|}{ QI Importance Questions }} & \multicolumn{3}{|c|}{ Overall } & \multicolumn{3}{|c|}{ Faculty } & \multicolumn{3}{|c|}{ Residents } \\
\hline & & Score & $\begin{array}{c}\text { Score } \\
\text { Got }\end{array}$ & $\boldsymbol{P}$ & Score & $\begin{array}{c}\text { Score } \\
\text { Got }\end{array}$ & $\mathbf{P}$ & Score & $\begin{array}{c}\text { Score } \\
\text { Got }\end{array}$ & $P$ \\
\hline 10 & $\begin{array}{l}\text { Quality improvement is mostly } \\
\text { another checkbox I have to check } \\
\text { off to meet unnecessary certification } \\
\text { requirements. }\end{array}$ & 33 & 25 & .211 & 36 & 9 & .032 & 32 & 29 & .775 \\
\hline \multicolumn{11}{|c|}{ QI Confidence Questions } \\
\hline 1 & $\begin{array}{l}\text { Quality improvement is feasible to } \\
\text { do in a typical busy primary care } \\
\text { clinic. }\end{array}$ & 30 & 31 & .87 & 18 & 45 & .186 & 33 & 27 & .428 \\
\hline 2 & $\begin{array}{l}\text { I have sufficient time to } \\
\text { meaningfully participate in quality } \\
\text { improvement projects. }\end{array}$ & 33 & 23 & .071 & 23 & 23 & .782 & 35 & 23 & .041 \\
\hline 3 & $\begin{array}{l}\text { I have sufficient technical support } \\
\text { and ability to use my EHR to } \\
\text { participate meaningfully in quality } \\
\text { improvement projects }\end{array}$ & 35 & 24 & .102 & 36 & 23 & .396 & 34 & 24 & .16 \\
\hline 4 & $\begin{array}{l}\text { I have sufficient staff and ancillary } \\
\text { support to meaningfully participate } \\
\text { in quality improvement projects. }\end{array}$ & 31 & 20 & .033 & 32 & 18 & .285 & 30 & 20 & .056 \\
\hline 5 & $\begin{array}{l}\text { My administration is supportive of } \\
\text { quality improvement projects that I } \\
\text { would like to implement in my own } \\
\text { practice. }\end{array}$ & 30 & 19 & .085 & 27 & 27 & .614 & 30 & 16 & .095 \\
\hline 6 & $\begin{array}{l}\text { I feel I have a good basic } \\
\text { understanding of quality } \\
\text { improvement concepts. }\end{array}$ & 32 & 11 & .004 & 18 & 9 & .414 & 35 & 11 & .005 \\
\hline 7 & $\begin{array}{l}\text { I feel confident in my ability } \\
\text { to participate in a quality } \\
\text { improvement project. }\end{array}$ & 35 & 15 & .002 & 27 & 14 & .19 & 37 & 15 & .004 \\
\hline 8 & $\begin{array}{l}\text { I feel confident in my ability to } \\
\text { initiate, design, and lead a quality } \\
\text { improvement project. }\end{array}$ & 41 & 19 & .001 & 23 & 32 & .644 & 47 & 15 & $<.001$ \\
\hline 9 & $\begin{array}{l}\text { I feel confident I can teach basic } \\
\text { quality improvement concepts to } \\
\text { other medical faculty and staff. }\end{array}$ & 44 & 16 & $<.001$ & 36 & 27 & .973 & 46 & 13 & $<.001$ \\
\hline 10 & $\begin{array}{l}\text { I feel confident that I can utilize } \\
\text { my quality improvement skills to } \\
\text { address issues in my own clinic. }\end{array}$ & 30 & 18 & .062 & 32 & 9 & .07 & 29 & 20 & .225 \\
\hline
\end{tabular}

Abbreviations: QI, quality improvement; EHR, electronic health record.

The two questions assessing potential negative perspectives on QI did not significantly improve following the project (reflected in a decreased score). Faculty reported a statistically significant improvement in the statement that continuous QI creates a positive teamwork atmosphere in the clinic $(P=.021)$, though there were no statistically significant responses to questions regarding confidence with QI.

Alternatively, residents did not report any statistically significant improvements in regards to QI importance, but improved significantly concerning confidence with QI. Residents reported improvement in feeling they had sufficient time for QI $(P=.041)$, had a good basic understanding of QI concepts $(P=.005)$, were able to participate in a QI project $(P=.004)$, initiate/design/lead a QI project $(P<.001)$, and that they could teach basic QI concepts to others $(P<.001)$.

The five additional questions in the postintervention survey assessing each participant's experience with the QI project were predominantly positive, with almost all results (median $=4$, interquartile range 
$[I Q R]=3-4)$ reflecting that they agreed they were able to meaningfully participate in the project, felt that the project created meaningful change in their clinic, participation was meaningful to themselves, and that they learned something valuable as a result. The majority of participants responded feeling neutral (median=3, IQR=3-4) when asked if they felt their input and ideas were a valuable part of the QI project.

\section{Discussion}

QI is important as it is frustrating to incorporate to the already overcrowded demands of academic medicine. It is essential to find novel ways to incorporate QI into family medicine academics. PBRNs offer one way to do this. This was a small pilot study of one American Board of Family Medicine maintenance of certification-style QI project done in a PBRN context. We have not yet been able to follow the data out long enough to see if this will affect educational outcomes for residents, however the significant increase in perceived ability to do their own QI and teach others to do QI is encouraging. The PBRN style did not seem to address two general issues of systemic change and overall attitudes toward QI for residents. Questions that addressed ability support from electronic medical records, administration, or ability to make changes in the residents' clinic did not change. However, given the short time period this may have been difficult to address. These factors are also notably outside the realm of residents' control. Questions addressing the residents' attitudes toward QI in general did not change significantly either; the data did not indicate why. Mixed-method format, larger study, multiple plan-do-study-act cycles, and longer time frames would help to address some of these issues.

Faculty did not show much change, except in that they thought QI improved teamwork. The low number of faculty makes it difficult to discuss causes. Faculty development is equally as important as resident development. Exploring ways ensure that QI projects meet faculty needs and expand their knowledge base needs to be addressed, and is a limitation of this paper.

Another limitation of this project is that is was voluntary, and the less than $50 \%$ participation rate. Most of those who did not participate were seniors who were about to graduate, possibly lowering their incentive to participate. However, this may also have skewed the results toward those more inclined to participated in QI and give it QIPs favorable reviews. The second surveys were collected before the accrual results of the QI project had been tabulated and reported back to the PBRN. It is possible that if we had waited until improvement in screening rates had been reported back to the programs, the results could have been more positive.

This is the first round of a continuous plan-do-study-act cycle that will be directed by the residents and faculty. This data will continue to be followed and developed through mixed methodology as further PDSA cycles are completed. The full potential of PBRNs have yet to be realized. Their efficacy as a QI teaching tool in academic medicine is an area of research that should be actively explored.
ACKNOWLEDGMENTS: The authors acknowledge the following individuals for their contributions to this study: Byron Jasper, MD, MPH; Emilio Russo, MD; Patrick O'Callaghan, PhD; Kiernan Smith, MD; Jim Theis, MD; Brian Gamborg, MD; Ernest James, MD; Amanda Phillips-Savoy, MD, MPH; Paula Rhode Bantley, PhD; and Sujeena Manandhar, MD.

FUNDING STATEMENT: This study was internally funded through the Department of Family and Community Medicine at Tulane University.

PRESENTATIONS: Data from this study were presented as a research in progress poster at the Society for Teachers in Family Medicine Conference on Practice and Quality Improvement, in December 2019, in Phoenix, Arizona.

CORRESPONDING AUTHOR: Address correspondence to Dr Clarissa Hoff, Department of Family and Community Medicine, 1430 Tulane Ave, \#8033, New Orleans, LA 70112. 504-9884700. Fax: 504-988-4701. choff@tulane.edu.

\section{References}

1. Accreditation Council for Graduate Medical Education. ACGME core program requirements for graduate medical education. http:// www.acgme.org/acgmeweb/Portals///PFAssets/ ProgramRequirements/CPRs2013.pdf. Accessed August 25, 2020

2. Massagli TL, Zumsteg JM, Osorio MB. Quality Improvement Education in Residency Training: A Review. Am J Phys Med Rehabil. 2018;97(9):673-678.

3. Philibert I, Gonzalez Del Rey JA, Lannon C, Lieh-Lai M, Weiss KB. Quality improvement skills for pediatric residents: from lecture to implementation and sustainability. Acad Pediatr. 2014;14(1):40-46.

4. Potts S, Shields S, Upshur C. Preparing Future Leaders: An Integrated Quality Improvement Residency Curriculum. Fam Med. 2016;48(6):477-481.

5. Lichkus J, Fang B, Peterson LE. Family Medicine Residency Graduates' Preparation for Quality Improvement Leadership. J Grad Med Educ. 2019;11(5):558-564.

6. Agency for Healthcare Research and Quality Improvement Practice Based Research Networks: An AHRQ Initiative. https://www.ahrq. gov/research/findings/factsheets/primary/pbrn/ index.html. Accessed August 25, 2020. 